\title{
Development and Application of Composite Materials in Civil
}

\section{Engineering}

\author{
Xiaofeng Shang ${ }^{1}$, Jiabin Lin ${ }^{2}$ \\ ${ }^{1}$ Chengdu University of Engineering and Technology, Chengdu, Sichuan, 610000
}

KEYWORDS: Composite Materials, Civil Engineering, Development, Application

\begin{abstract}
An important factor in civil engineering to promote social progress and economic development, civil engineering involves the use of many of the materials and equipment. In order to improve the stability and reliability of civil engineering, science needs to use the material. Composite material is a material having a high performance and low power consumption, in line with the needs of civil engineering construction, and meets the low-carbon green design. The following article on the development of composite materials in civil engineering started to explore, and the actual situation of civil engineering, composite materials in civil engineering applications described, to provide reference for the relevant personnel, improve the level of application of composite materials, to promote the construction of civil engineering quality standards to achieve economic and social value of civil engineering projects.
\end{abstract}

\section{Introduction}

Civil engineering composites mainly refers to fiber-reinforced composite material can be effectively applied to engineering structural reinforcement in civil engineering structures to promote stability and reliability is guaranteed, reduce security risks occur. Civil engineering composites having a strong design, high safety factor, strong corrosion resistance characteristics, can be widely applied to civil engineering construction, maintenance, and can effectively improve the quality of civil engineering construction, reduce all kinds of accidents happened. With the composite processing technology means progress and improvement of composite materials in civil engineering application of continuous improvement, so that the construction of civil engineering technology and construction processes are fully progress.

\section{The Characteristics and Development of Composite Materials in Civil Engineering}

Civil engineering composites mainly refers to fiber-reinforced composite material, referred to as FRP, mainly for reinforcing fiber materials and basic materials through effective process to form a composite material having a strong application value. (1) the composite materials having strong design, composite materials according to the actual needs of the project, different design requirements, can effectively improve the stability and reliability of civil engineering. (2) the composite material has good corrosion resistance, longer service life and shear resistance, can be widely applied to civil engineering construction, civil engineering to promote the safety factor has been effectively improved. (3) the composite material can effectively adjust the appearance of civil engineering, composite materials by color control, civil engineering change the traditional single color in a simple manner, to promote civil engineering more in line with people's aesthetic 
standards. (4) the composite material can be effective for civil engineering structural noise and vibration control, prompting years of service of civil engineering has been improved.

The composite material by adding a binder such composite structural members and civil engineering combine to promote the carrying capacity of the member of civil engineering, shear resistance and durability can be improved. Early use of composite materials in civil engineering mainly through the composite corrosion and durability of the characteristics of applications, the composite material as the anti-corrosion materials in civil engineering concrete and steel. With the improvement and progress in the field of preparation and application of technology in line with the material, the composite material should be reinforced in civil engineering technology has been widely recognized. Composite reinforcement technology effectively to enhance the seismic capacity of civil engineering has been to promote civil engineering able to withstand more natural interference factors. The composite material is mainly applied to civil engineering in reinforced concrete beams and other materials to promote stability and reliability engineering comprehensive upgrade. As reinforced by the deepening technology research and improvement, composite reinforcement technology used in the structure and direction of development has gradually become a new hotspot and composite reinforcement technology.

\section{The Application Analysis of Composite Materials in Civil Engineering}

Composite materials are mainly fiber-reinforced material is applied in the actual civil engineering, composite reinforcement technology, can effectively improve the reliability and stability of the civil engineering components, reducing the incidence of various types of security risks, prompting civil engineering quality can meet the design standards, promote the upgrading of its service life.

In line with the material composite structure is combined with other materials through the composite material to promote the advantages of each material can be between the full, in the form of a composite material combinations, prompting complete the basic functions on the integrated nature of the full upgrade of the new structure, promote the overall effect of civil engineering has been effectively improved.

Composite concrete structures, reinforced concrete structures in civil engineering will be used, but the reinforced concrete structure has some shortcomings, such that the mechanical properties of reinforced concrete structures and corrosion resistance is not strong enough in a number of civil engineering can not be expected Effect. In line with the application of concrete material, effectively improve the corrosion resistance of concrete, durability, the mechanical properties of a structure more in line with the needs of civil engineering, civil engineering and even can effectively improve the seismic level. Such as: composite material - concrete composite slab use, can effectively improve the reliability and shock resistance slab.

Composite material - a combination of wood components, wood materials in the course of civil engineering, the material itself is affected by the nature of the wood, causing the fire resistance of wood is not strong enough, resulting in civil engineering of fire safety hazards. By composite material - a combination of wood, its mechanical properties can be optimized effectively, and to promote wood fire rating upgrade, reduce security risks occur.

Composite materials - aluminum composite members, will wrap onto the surface of aluminum composite materials to improve shear resistance of aluminum alloy, aluminum alloy materials to avoid deformation, etc., to promote the application of horizontal aluminum alloy member be fully promotion. 
All-composite components, primarily through the application of the composite material, the composite material is applied to civil engineering, applied to different parts, and promote the quality of civil engineering has been fully improved.

Preparation of composite web member is compiled by the slats made of composite materials, composite materials prepared by using network member, can fully improve the reliability of large-span structure of large civil engineering.

Light Bridges composite material, the composite material can be used as pedestrian bridge some of the main material, prompting a lightweight bridge has good carrying capacity, to meet people's travel needs.

Smart composites, Smart Composites can effectively eliminate a number of electromagnetic waves, and static electricity control, can effectively improve the quality of construction of civil engineering.

\section{Conclusion}

Civil Engineering is the urbanization of the important part, is the key factor of social progress and economic development. In civil engineering construction process, will produce large amounts of material consumption. By application of composite materials in civil engineering, can effectively improve the safety and stability of civil engineering, prompting civil engineering can meet the design standards, reduce security risks occur. Analysis of different types of civil engineering application of composite materials, composite materials obtained in the development of civil engineering, the development of clear direction in civil engineering composites, promote upgrading civil engineering construction, civil engineering to achieve economic and social benefits .

\section{REFERENCE:}

[1] Feng Peng. development and application of composite materials in civil engineering [J]. Fiber Reinforced Plastics / Composites, 2014,09: 99-104.

[2] Sha Zhenghui. development and application of composite materials in civil engineering [J]. Chinese and foreign entrepreneurs, 2015,18: 222.

[3] Zhao Liyan. Development and Applications [J]. on composites in civil engineering building materials Jiangxi, 2015,21: 266-267.

[4] Wang Qian. Application Progress of fiber composite materials in civil construction engineering [J]. knowledge economy, 2012,06: 93. 